\title{
Sexual Harassment in the Workplace: Case Study of the Nigerian Legal Sector
}

\author{
Adetutu Deborah Aina-Pelemo*1 $\quad$ M. C. Mehanathan $(\mathrm{PhD})^{1} \quad$ Pradeep, Kulshrestha $(\mathrm{PhD})^{1}$ \\ Iseoluwa Titilayo Aina ${ }^{2}$ \\ 1.Department of Law, Sharda University, Greater-Noida, Uttar-Pradesh, India. \\ 2.Department of law, Afe Babalola University, Ado-Ekiti, Ekiti State, Nigeria.
}

\begin{abstract}
:
Sexual Harassment has been a habitual phenomenon among legal professionals. Consequently, "suffering and smiling" is the concealed solution to this challenge due to the importance of livelihood and career development. This study seeks to examine the prevalence of sexual harassment within the Nigerian legal profession, whether there is need for the victims to be protected and provided with legal structure to confidently report issue of sexual harassment, and whether there is a need for domestic law for the society. Empirical and descriptive research methods were adopted, 561 Nigerian lawyers were surveyed using a structured questionnaire. Data were collected and analyzed using frequencies, chi-square, chart, regression and correlation analysis. It revealed that there is no adequate social structure for addressing sexual harassment and prolonged exposure to sexual harassment has disguised its true effect on the victims. Thus, there is a need for professional regulation to combat sexual harassment among the lawyers.
\end{abstract}

Keywords: Behavioural adaptation; Nigerian legal professionals; National Industrial Court of Nigeria; Unprofessional behaviour: Sexual harassment in the workplace

DOI: $10.7176 / \mathrm{JLPG} / 86-13$

Publication date: June $30^{\text {th }} 2019$

\section{Introduction}

Universally, sexual harassment in the workplace is a major challenge faced by most organisations (Page and Pina, 2015). Ninety-one percent of 487 nurses/nursing students within five medical centers in Israel experienced at least one type of sexual harassment in their workplaces (Bronner et al., 2003). Approximately, 62\% of 500 Saudi university hospitals medical staff surveyed reported being victim of harassment (Aljerian et al., 2017). Sexual harassment is a serious concern within the public accounting profession (Miller and Landgraf, 2010). The Lebanon survey conducted in the hospitality industry revealed that $28 \%$ of 100 participants were sexually harassed (Hussin, 2015). Similarly, 48\% of 3001 policemen and $64 \%$ of 1, 295 policewomen surveyed in Netherlands, experienced one or more forms of sexual harassment (Haas et al., 2009). The USA survey conducted among the social work master and bachelor students revealed that $55.7 \%$ of 515 participants experienced one incident of sexual harassment in their field of practice (Moylan and Wood, 2016).

Within the legal profession, there are several reports of sexual misconducts in the developed countries: of 451 women working in Canada, including legal professionals surveyed by InsightsWest (2017), 54\% experienced sexual harassment and $30 \%$ were subjected to sexual conducts as a ground for promotion and advancement in their workplace. Women's Legal Education and Action Fund of Canada revealed that 30\% of 1,178 participants selected from most workplaces experienced sexual harassment (Government of Canada, 2017). The survey conducted by the American Bar Association among 3000 participants, revealed that $68 \%$ females and $19 \%$ males experienced sexual harassment (Rubino, 2018). In fact, rampant sexual behaviours within the American law firms are: unwanted hugging, back-patting, shoulder rubbing, lustful comments, kissing, inappropriate fondling and seductive leering (Rikleen, 2018). In the English law firms, about two-third of the female lawyers surveyed experienced sexual harassment (Stanley, 2017). It was also revealed that of 1000 participants surveyed, $42 \%$ experienced either unwanted touch, or evocative comments, or propositioning while working in their law firms (Financial Times, 2018). Likewise, fifty percent female attorneys surveyed by the California State Bar experienced sexual harassment (Chang and Chopra, 2015).

The 114-sample drawn by the International Bar Association (IBA) among advocates from Australia, America, Asia, Africa and Europe exposed that $27 \%$ females and $7 \%$ males experienced sexual harassment (Ellis and Buckett, 2017). Another survey conducted by the IBA among 6000 advocates across the globe, revealed that one in three females experienced sexual harassment and one in three males reported been bullied within the profession (Legal Insights, 2018) . It was reported that a law intern was sexually harassed in one of the most reputable law firm in New-Zealand (Eleanor, 2018). Of a fact, sexual harassment rife in the legal profession with high number of reports in developed countries as compared with the developing countries (LawyerPerformanceProject, 2017), because they have attained the boldness of overtly disabusing sexual harassment, which is worth reproducing in the developing world. In India, it was reported that a legal intern was sexually harassed by the then Supreme Court Judge (Kothari, 2013). Equally, an acting Supreme Court Justice of 
New York was reported to have sexually harassed a law clerk within Manhattan commercial division (Hamilton, 2018). All these reports show that sexual harassment within the legal profession is an issue to be taken seriously. However, issue of this nature in the Nigerian Bar Association and some notable legal forums is yet in the limelight. Before proceeding with the theme of discussion, it is essential to define sexual harassment at workplace within the purview of the National Industrial Court of Nigeria (NICN), being the Court nationally saddled with the responsibility of hearing such matters. According to Convention on Elimination of Discrimination Against Women (CEDAW) General Recommendation 19, sexual harassment is defined to include-

'such unwelcome sexually determined behaviour as physical contact and advances, sexually coloured remarks, showing pornography and sexual demands, whether by words or actions. Such conduct can be humiliating and may constitute a health and safety problem; it is discriminatory when the woman has reasonable grounds to believe that her objection would disadvantage her in connection with her employment, including recruiting or promotion, or when it creates a hostile working environment'

Remarkably, Hersch discovered in his research that about Seventy-Eight (78) countries have nationally defined or structured legislative provision for defining the term 'sexual harassment' with the exclusion of Nigeria (Hersch, 2015). Thus, the (CEDAW) definition has been adopted for the purpose of this article, as it is one of the major bases for national discussion and adjudication of issue relating or incidental to sexual harassment in NICN. Nationally, of the thirty-six (36) States and Federal Capital Territory of Nigeria, only Federal Capital Territory (FCT) and Lagos State have a precise definition of sexual harassment in the workplace and this applies to only residence of those terrains (ViolenceAgainstPersonsProhibitionAct, 2015). In fact, the Nigerian labour / criminal law has no specific provision for sexual harassment in the work place till date, although there is an on-going Bill (lawPavilion, 2016), to criminalize, prevent, prohibit and redress issues of unwanted sexual misconduct within the tertiary educational institution alone. But the Third Alteration Act, 2010 of the Constitution of the Federal Republic of Nigeria (CFRN) empowers the National Industrial Court (NICN) to adjudicate on matters of sexual harassment based on the international treaties i.e. (International Labour Organisation 'ILO', African Charter on Human and Peoples' Rights, and 'CEDAW' conventions \& Recommendations) signed, ratified and yet to be domesticated by the National Assembly (Ejieke Maduka $\mathrm{V}$ Microsoft Nigeria Limited and 2 Ors 2013) ${ }^{1}$.

Previous research has expressed the difficulty in defining sexual harassment generally, specifically in a country with little or no legal framework (Nwaeke, 2015). In most instances, it will be difficult to draw the thin line between gender harassment and sexual harassment (Quick and McFadyen, 2016). Emphatically, sexual harassment in Nigeria is more challenging, because there is no clear-cut legislation that explicitly defines what constitutes sexual harassment as well as no provisions to punish offenders of the act (Aja-Okorie, 2014). This indicates that decisions of NICN in about nine (9) sexual harassment cases decided were based on mere guidelines and distinctive discretion. In the absence of a comprehensive definition of sexual harassment in Nigeria and for proper explanation, may we lend the succinct definition of sexual harassment from Cortina and Berdahl's study, where they view sexual harassment from two different viewpoints: legally, and sociopsychologically (Cortina and Berdahl 2008). According to the legal definition of sexual harassment by the US Equal Employment Opportunity Commission (EEOC), 1980 through Title VII of the Civil Rights Act, 1964 (as amended), sexual harassment includes:

'Unwelcome sexual advances, requests for sexual favours, and other verbal or physical conduct of sexual nature constitute sexual harassment when-

1. Submission to such conduct is made either explicitly or implicitly a term or condition of an individual's employment;

2. Submission to or rejection of such conduct by an individual is used as the basis for employment decisions affecting such individuals or;

3. Such conduct has the purpose or effect or unreasonably interfering with an individual's work performance or creating an intimidating, hostile, or offensive working environment (29 C. F. R. 1604.11 (1980)';

Socio-psychologically, sexual harassment denotes a two-way tool. i.e. the victim's experience and the response to the unwelcome sexual behaviours (Fitzgerald et al., 1997). From the layman's view, sexual harassment has diverse meanings depending on one's perception. The environment, type, and structure of organisation where sexual behaviour occurs, may influence the perception of what sexual harassment is or not (Aina and Kulshretha, 2017; O'Connor et al., 2004). Most youth, students and teachers surveyed in Edo-State, Nigeria view sexual harassment as an ultimate part of human life (Imonikhe et al., 2012; Okoro and Obozokhai,

\footnotetext{
${ }^{1}$ The pioneer case of sexual harassment in Nigeria: Ejieke Maduka v Microsoft Nigeria Limited and 2 Ors, NICN/LA/492/2012 (National Industrial Court, Lagos Division December 19 ${ }^{\text {th }}, 2013$ ); International Labour Organisation Discrimination ( Employment and Occupation) Convention 1958 No 111; African Charter on Human and Peoples Rights (Ratification and Enforcement) Act CAP A9, LFN 2004; United Nations Convention on Elimination of All Forms of Discrimination against Women (CEDAW), 1979.
} 
2005). In fact, most Nigerian organisations perceive sexual harassment in the workplace as the personal problem of the employer-employee that needs to be resolved by them (Ladebo, 2003).

Based on this study and from the data collected, sexual harassment involves unwanted deliberate touch, turning work discussions to sexual topics, asking personal questions about sexual life, sexual comments about the person's clothing or look, unwanted sexual looks or gestures, intimidation and threatening of employees for sex, and conditioning the job benefits, or promotion to sexual favour. At this juncture, it is apposite to discuss how Nigerian culture aids sexual harassment before deliberating on previous and current research of the country.

\subsection{Sexual Harassment and Nigerian Culture}

The impact of culture on sexual harassment in Nigerian organisation evaluated, showed that 8 out of 10 interviewees in their study reported their harassers, but no serious action was taken against them by the relevant authority at work, while some laughed it off, and chastised the victim for arousing the sexual drive of the harasser (Ige and Adeleke, 2012). The reaction is not farfetched due to the patriarchal structure of the society where men are seen as important and women as commodity. In those days when the land was troubled, the parents would rather protect the men than the women (Izugbara, 2001). Also, Nigerian culture frowns against open discussions of sexual dialogs, so the victims prefer to imbibe the culture of silence (Awosusi and Ogundana, 2015; Izugbara, 2004). This disposition is appalling and further encouraged by the inadequate legal structure prohibiting sexual harassment in the country.

Nigeria being a country with diversified religion, language, and overlapping ethnicity of about 374 groups, coupled with distinct regional boundaries will directly and indirectly encourage diverse forms of discrimination and harassment (Cohn, 2013), especially in terms of gender discrimination in employment. For clarity, it is essential we state that Nigeria comprises of 36 States, a Federal Capital Territory, Abuja, and geographically having 6 regions of diverse population. It further characterised into North Central, North East, North West, South East, South-South, and South West (Aina-Pelemo and Saluja, 2018). The dominant ethnic groups are Hausa, Yoruba, and Igbo; they all accord superiority to male as the head of homes in these major groups, so the sexual offences, and extra-marital affairs of men in this society is sanction-free and regarded as a norm to endure including domestic violence (Odebiyi, 1992).

In support of this diversification in culture and character, some of the South-Eastern regions have strong preference for male child (Inyang-Etoh and Ekanem, 2016; Okeke et al., 2015; Nnadi, 2013), since most of their customary rites are strictly performed by men. In the same way, a State (Plateau) among the North-East recommends purification ritual to women who give birth to female children, to neutralise the ill-luck female children bring (Izugbara, 2004). Also, religiously and customarily, Nigerian men have the right to marry more than one woman. All these unchanged behaviours, customs and mind-sets have been transported into workplaces and harassers go blameless which discourage the victims from taking necessary steps in protecting their rights to dignity and decent working conditions.

\subsubsection{Sexual Harassment and Various Nigerian Work Facets}

From time immemorial and till date, sexual harassment has been reported as a persistent problem in Nigerian educational system (Adamolekun, 1989). Of the sixty selected female teachers in primary and secondary school of Idah local government, Kogi-State, 50\% experienced sexual harassment in their workplaces (Idris et al., 2016). In a study conducted by (Abe, 2012) on two selected universities in Lagos, the respondents experienced different categories of sexual harassment; ranging from physically and verbally harassed behaviours, to physically assaulted behaviours. The prevalent form of sexual harassment in Nigerian university settings is that from faculty/staff to the female students (Akanle, 2011). The study conducted on 413 female students of the University of Port-Harcourt by Mezie-Okoye and Alamina revealed that $46.7 \%$ experienced sexual harassment (Mezie-Okoye and Alamina, 2014).

Recent findings reported that sexual harassment booms within the Nigerian banking sector (Akinfala and Komolafe, 2017; Bello, 2016; Alooma and Atadiose, 2014; Fapohunda, 2014). Adenugba and Ilupeju (2012) also noted that $80.8 \%$ of the respondents were sexually harassed and $94.2 \%$ respondents agreed that female marketers face numerous risks in the course of executing and retaining their jobs. In fact, (Bello, 2016) emphasised that 58.38\% male and 53.51\% female surveyed, experienced and view sexual harassment as a challenge to the growth of Nigerian banking sector. The form of sexual harassment experienced by employees within the government or public organisation varies, precisely at Lagos State Civil Service Commission, Alausa: it ranges from unwanted touch, sex-related gesture, sexual remarks, money enticement and intimidation (Yusuf, 2008). Correspondingly, previous research also carefully mapped the ways sexual harassment affects the Nigerian medical sector. Both the male and female professionals experience this societal evil, and it is majorly perpetrated by senior colleagues, co-mates, patients and friends to the professionals (Abodunrin et al., 2014; Arulogun et al., 2013).

Observably, there are ample researches on sexual harassment within the Nigerian educational, banking, and medical sectors, but there is little or no research within the legal, telecommunication, entertainment, financial, 
military and paramilitary sectors. However, (Amos, 2016) reported that the Nigerian women police of the selected survey are victim of discrimination, intimidation, sexual harassment and hostile environment in the course of their day to day work activities. Especially in the area of posting when the senior rank officers either demand for sexual gratification or money in exchange for good posting, which is ordinarily one of the officer's primary duty.

Nevertheless, our point of controversy is whether the Nigerian legal profession is affected by the societal trend called sexual harassment? (Ladebo, 2003) reported that sexual harassment permeates all facets of Nigerian national life and he further referred to the statement of one of his respondents- 'even at the bench, there is harassment, so who is going to judge the case?' Although this statement was uttered by an interviewed judge prior the Constitutional empowerment of the (NICN) to adjudicate on sexual harassment matters. However, till date there is no statistical proof of this assertion, neither at the bar nor at the bench. This is one of the gaps this study seeks to fill. In a conference organised by the International Bar Association in 2009, Adekoya, a Senior Advocate of Nigeria (SAN), (Adekoya, 2009) acknowlegded that female lawyers face certain problems within the profession, ranging from; gender-discrimination to gender pay-gap, with explicit exclusion of sexual harassment, although gender-discrimination is one of the types of sexual harassment according to Fitzgerald and Ormerod which cannot be easily detached from sexual harassment in the workplace (Fitzgerald and Ormerod, 1991).

Based on our observation, there is no research on sexual harassment and legal sector or workplace violence faced by Nigerian legal practitioners especially the women. Is it that the lawyers are not vulnerable to sexual harassment or they also suffer in silence like other professionals? as reported by some researchers (Amazue et al., 2014; (Ezichi et al., 2013) that victims of sexual harassment suffer in silence especially the bankers. It was further argued that it can be easily found in entertainment industry, government offices, and private organisations, though some professions are more prone to it (Gupta, 2014). Therefore, should legal profession be added to the list of professions that are more prone to sexual harassment? All these gaps prompted the authors to embark on this survey, in order to statistically and empirically justify whether sexual harassment exist within the Nigerian legal profession. In our study, we examined the prevalence of sexual harassment among the Nigerian legal professionals, causes, frequencies of occurrence, duration, their level of awareness and the inability of the NICN to address sexual harassment cases, as well as consequences of sexual harassment.

\section{Research Questions}

- Does sexual harassment (SH) occur within the Nigerian legal sector?

- What is the prevalence of sexual harassment among the Nigerian Legal Professionals by gender?

- Do Nigerian Legal practitioners fall victim of sexual harassment at workplace due to low level of knowledge of the act?

- Is there a need for legal protection of the Nigerian legal professionals (NLP) from sexual harassment in the workplace?

\section{Research Hypotheses}

1. There is no effective policy that maintains and sanctions employers/employees against sexual harassment in the workplace or court.

2. There is no relationship between awareness of the lawyers about the empowerment of the National Industrial Court of Nigeria and its ability to prevent the workplaces from sexual harassment.

3. Prolonged exposure to sexual harassment has led to the development of coping mechanism which masks its true nature and consequences on the victim.

4. There is no relationship between the prevalence of sexual harassment in the legal profession and the necessity for legislative protection.

\section{Methodology}

\subsection{Participant and Procedure}

To ensure a nigh accurate response, a pilot study was conducted on 40 subjects within February to April, 2017 , afterwards, a few minor changes were made on the original research instrument (questionnaire) based on the respondents' feedback (Joubert et al., 2011). It is worth noting that the questionnaire was structured in anonymity due to the calibre of the participants surveyed and the sensitivity of the topic. The revised structured online or internet questionnaire was displayed or uploaded on google drive and disseminated to the target population via different Nigerian legal social groups, such as- collective email, WhatsApp, LinkedIn, and Facebook (Clancy et al., 2014). Due to the low response of the respondents through on-line survey, the paperand-pencil method was subsequently adopted for the completion of data collection (Loughnan et al., 2013). We approached the Abuja residence lawyers at legal gatherings, offices and court rooms for the data collections within the period of August 2017 to January 2018. Of about 780 questionnaires distributed, only 561 Nigerian 
lawyers provided the necessary information for this survey (Vosylis et al., 2012). The sampling was selected randomly through a purposive and stratified sampling technique due to the variables and objective of the study, as well as the various locations that the data was collected. The sample size was drawn from selected population of Federal Capital Territory, Abuja Nigeria due to the fact that it is the seat of power and sexual harassment have been criminalized since 2015 by ViolenceAgainstPersonsProhibitionAct (2015) in this region and still, there is neither a significant report nor empirical study on sexual harassment and its effect on the people.

Measure

The analysis of the data collected was done by the use of IBM Statistical Package for Social science (SPSS) 20. The 29 questions contained in the questionnaire were sectionalized into eight parts according to the (4) research questions and (4) hypothesis raised. Descriptive statistics involving frequencies and percentages was used to compute the participants' demographics and the research questions. While the first and second hypotheses were measured by partial correlation, third by Pearson chi-square and fourth by regression analysis (Haas et al., 2009; Ismail et al., 2007; Berdahl, 2007a).

\subsubsection{The Participants' Experiences}

The focus group discussions and the open-ended session of the research instrument (questionnaire) revealed the following information:

"II was subjected to torture, and emotional blackmail. I was made to believe I was not good at any other thing than sex. In order to keep my job, I had to play to the tunes of my head of chambers. He can even come to my house at odd hours and I could not say no, all because I wanted to keep my job. When I started refusing his sexual advances, it got so bad that he almost assaulted me. Started picking on me, and ended up giving me an indefinite suspension'

'I know of a friend who resigned from her work place because she has been harassed by her boss and the office is in his house, she was so scared at the fact that if he rapes her or does something worse, that there will be no one to help her.'

'Yes, I was a victim of sexual harassment and my employer sleeps with almost all the employees including the interns. He also creates enmity amidst all employees in order to divide and rule us. I got tired of dancing to his tune since he places the official benefits on the employee's ability to subject herself to his demands, I revolted by confronting him, then he first suspended me and while the suspension was going-on, he directed I'm served with termination letter at home. A year after, he terminated another colleague because she also got tired of messing with him.'

'I am a victim of sexual harassment, but when it is coming from a superior which is mostly the case, how should I cope with it?'

'My experience took place years ago, when I was still very young and single. I really had nobody to report to, but a senior colleague and my pastor. Eventually, I was 'sacked' by my then boss. If there is a proper framework in place, no young lawyer should have to experience what I went through, which included near rape. Those responsible for strategizing against sexual harassment in the legal profession should see it as a serious calling. Thank you.'

'A past employer, who is a senior lawyer, pushed his body against mine forcefully and used his hands to rub through my body. After I pushed him and ran away, he started victimizing me at the office. Prior my resignation, I spoke to him about it and he was gracious enough to listen and apologized. I still resigned.'

'My biggest fear is joining the corporate world because I will or may be sexually harassed. To minimize the chances, I ensured I work with firms that are affiliated with my family. The forms of sexual harassment I have experienced were at the hands of the client(s). since I was working with my family's firm, it was quickly nipped in the bud.'

'Most lawyers especially the SAN's are very, very, guilty of this act and I have been a victim. Please something should seriously be done about this and be done quickly. ASAP! So many junior lawyers suffer from this in silence.'

'Though I have never been harassed sexually at my work place largely, because of how I dress and respect myself, a lot of other colleagues- men and women have, particularly by their bosses (male and female). Some of them willingly, some unwillingly. But having a law in Nigeria which punishes 
offenders will put a lot of men and women in check and give courage to the victims to speak out...'

\section{Results}

5.1 The findings on demographic characteristics of the participants are presented in Table 1.

Table 1: Demographical Characteristics of the Participants

\begin{tabular}{lll}
\hline Items & & Frequency \\
\hline Gender & Male & $222(39.6 \%)$ \\
Marital Status & Female & $339(60.4 \%)$ \\
& Married & $269(48.0 \%)$ \\
& Single & $278(49.6 \%)$ \\
Institution & Divorced & $11(2.0 \%)$ \\
& Separated & $3(0.5 \%)$ \\
& Ministry of Justice & $55(9.8 \%)$ \\
& Private Law Firm & $431(76.8 \%)$ \\
& The Judiciary & $22(3.9 \%)$ \\
& Government Legal Parastatal & $28(5.0 \%)$ \\
& Law universities & $25(4.5 \%)$ \\
& Senior Advocate & $4(0.7 \%)$ \\
& Head of Chambers & $85(15.2 \%)$ \\
& Associate Counsel & $127(22.6 \%)$ \\
& Senior Counsel & $93(16.6 \%)$ \\
& Counsel & $157(28.0 \%)$ \\
& Senior State Counsel & $12(2.1 \%)$ \\
& State Counsel & $8(1.4 \%)$ \\
& Administrative Staff & $21(3.7 \%)$ \\
& Partner & $53(9.4 \%)$ \\
& Judge & $1(0.2 \%)$ \\
& Less than 20 years & $11(2.0 \%)$ \\
& Between 20 and 30 years & $210(37.4 \%)$ \\
& Between 30 and 40 years & $220(39.2 \%)$ \\
40 years and above & $120(21.4 \%)$ \\
\hline
\end{tabular}

5.1.1 Research Question 1: Does sexual harassment (SH) occur within the Nigerian legal sector?

The occurrence of SH among participants in terms of forms experienced- range from unwanted deliberate touching, turning work discussions to sexual topics, asking personal questions on sexual life, sexual comments about the person's clothing or look, to unwanted sexual looks or gestures; Frequency of SH ranges from very occasionally to rarely; Colleagues' experience and the impact of SH on the growth of the profession is shown in Table 2 below. This indicates that there is high occurrence of SH in the Nigerian legal profession.

Table 2: Occurrence of Sexual Harassment within the Nigerian Legal Sector

\begin{tabular}{|c|c|c|c|}
\hline $\mathbf{S} / \mathbf{N}$ & Items & & Frequency \\
\hline \multirow[t]{7}{*}{1.} & Form(s) of & Unwanted deliberate touching & $74(13.2 \%)$ \\
\hline & experienced & Turning work discussions to sexual topics & $55(9.8 \%)$ \\
\hline & & Asking personal questions on sexual life & $23(4.1 \%)$ \\
\hline & & $\begin{array}{l}\text { Sexual comments about the person's } \\
\text { clothing or look }\end{array}$ & $22(3.9 \%)$ \\
\hline & & Unwanted sexual looks or gestures & $71(12.7 \%)$ \\
\hline & & All of the above & $83(14.8 \%)$ \\
\hline & & No experience & $\begin{array}{l}233 \\
(41.6 \%)\end{array}$ \\
\hline \multirow[t]{5}{*}{2.} & How frequent do you experience sexual & Very Frequent & $19(3.4 \%)$ \\
\hline & harassment at your workplace? & Frequent & $50(8.9 \%)$ \\
\hline & & Occasionally & $134(23.9 \%)$ \\
\hline & & Rarely & $115(20.5 \%)$ \\
\hline & & Never & $243(43.4 \%)$ \\
\hline \multirow[t]{2}{*}{3.} & Have your colleague ever experienced & Yes & $356(63.5 \%)$ \\
\hline & $\begin{array}{l}\text { any form of sexual harassment at } \\
\text { workplace you are aware of? }\end{array}$ & No & $205(36.5 \%)$ \\
\hline \multirow[t]{2}{*}{4} & Does sexual harassment hinder the & Yes & $469(83.6 \%)$ \\
\hline & growth of legal profession? & No & $92(16.4 \%)$ \\
\hline
\end{tabular}




\section{Research Question 2:}

Fig 1: what is the prevalence of sexual harassment among the Nigerian Legal Professionals by gender?

5.1.2 Figure 1: shows that $68.0 \%$ of female participants in the study experienced Sexual Harassment as compared to $32.0 \%$ male that experienced same. This suggests that female lawyers are more vulnerable or prone to sexual harassment in the profession.

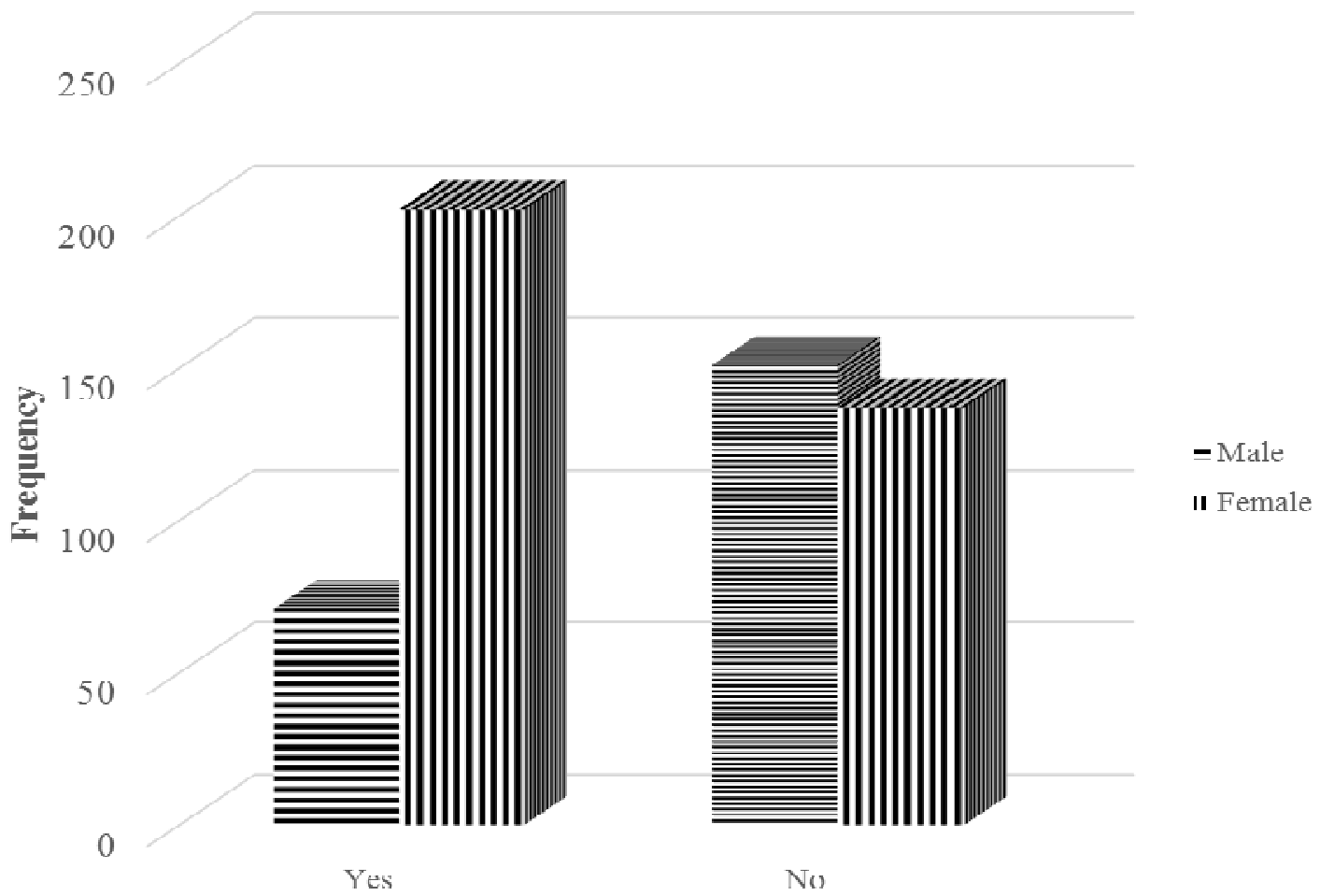

Response on Sexual harassment experience

Figure 1: Experience of Sexual Harassment by Gender

Research Question 3: Do Nigerian Legal professionals fall victim of sexual harassment at workplace due to low level of knowledge of the act?

5.1.3 Based on the response of the participant to (5) basic questions centring on the knowledge of sexual harassment,

Table 3 depicts that there is a high level of knowledge of sexual harassment among the professionals, but the knowledge of the participants does not secure them from being harassed.

Table 3: Awareness and Knowledge of sexual harassment among the Nigerian Legal Professionals

\begin{tabular}{|c|c|c|c|}
\hline $\mathbf{S} / \mathbf{N}$ & \multicolumn{2}{|c|}{ Items } & \multirow{2}{*}{$\begin{array}{l}\text { Frequency } \\
544(97.0 \%)\end{array}$} \\
\hline 1. & Have you heard of the term sexual & Yes & \\
\hline & harassment in the workplace before? & No & $17(3.0 \%)$ \\
\hline & Through what means was the term & Official orientation & $81(14.4 \%)$ \\
\hline & sexual harassment heard? & Seminars/conferences & $81(14.4 \%)$ \\
\hline & & Experience & $125(22.3 \%)$ \\
\hline & & Media / Books & $226(40.3 \%)$ \\
\hline & & Parents / Peers & $40(7.1 \%)$ \\
\hline & & None & $8(1.4 \%)$ \\
\hline \multirow[t]{7}{*}{3.} & Harassment & Unwanted deliberate touching & $128(22.8 \%)$ \\
\hline & mean? & Turning work discussions to sexual topics & $26(4.6 \%)$ \\
\hline & & Asking personal questions on sexual life & $13(2.3 \%)$ \\
\hline & & $\begin{array}{l}\text { Sexual comments about the person's } \\
\text { clothing or look }\end{array}$ & $17(3.0 \%)$ \\
\hline & & Unwanted sexual looks or gestures & $96(17.1 \%)$ \\
\hline & & All of the above & $269(48.0 \%)$ \\
\hline & & None of the options & $12(2.2 \%)$ \\
\hline \multirow[t]{2}{*}{4.} & What are the likely causes of sexual & Power intoxication & $103(18.4 \%)$ \\
\hline & harassment at workplace? & Patriarchal structure of Africa & $21(3.7 \%)$ \\
\hline
\end{tabular}




\begin{tabular}{clll} 
S/N & Items & Frequency \\
$119(21.2 \%)$ & $299(53.3 \%)$ \\
& & Lack of domestic law and official policies & $19(3.9 \%)$ \\
& & All of the above & $85(15.2 \%)$ \\
$5 . \quad$ Which of the consequences of sexual & No idea & Low performance & $88(15.7 \%)$ \\
& harassment at workplace is rampant & Resignation & $151(26.9 \%)$ \\
& to your knowledge? & Endurance/Tolerance & $72(12.8 \%)$ \\
& & Psychological and Health challenges & $145(25.8 \%)$ \\
& All of the above & $20(3.6 \%)$ \\
\hline
\end{tabular}

Research Question 4: Is there a need for legal protection of the Nigerian legal professionals (NLP) from sexual harassment in the workplace?

5.1.4 Presented in Table 4 depicts that mandatory provision of internal official provision, amendment of legal practitioner' Act/Rules and setting up of a body with confidential procedures to address issues of sexual harassment could serve as long-term solution to $\mathrm{SH}$ in the legal profession, and there is need for law to prohibit/sanctions sexual harassment at workplace base on the total percentage $(91.1 \%)$ participants in agreement to this.

Table 4: Frequencies to determine the need for the protection of the NLP vis-à-vis Sexual Harassment

\begin{tabular}{|c|c|c|}
\hline & Items & Frequency \\
\hline \multirow{5}{*}{$\begin{array}{l}\text { What is the long-term solution to } \\
\text { sexual harassment in the legal } \\
\text { profession? }\end{array}$} & Mandatory provision of internal official policy & $61(10.9 \%)$ \\
\hline & $\begin{array}{l}\text { Amendment of the legal practitioners' Act/ } \\
\text { Rules }\end{array}$ & $15(2.7 \%)$ \\
\hline & $\begin{array}{l}\text { Setting up a body with confidential procedure to } \\
\text { address such issue }\end{array}$ & $75(13.4 \%)$ \\
\hline & All of the above & $362(64.5 \%)$ \\
\hline & It does not hinder the growth of the profession & $48(8.6 \%)$ \\
\hline \multirow{5}{*}{$\begin{array}{l}\text { There is need for a law in Nigeria } \\
\text { that punishes sexual harassment at } \\
\text { workplace? }\end{array}$} & Strongly Disagree & $15(2.7 \%)$ \\
\hline & Disagree & $5(0.9 \%)$ \\
\hline & Neutral & $30(5.3 \%)$ \\
\hline & Agree & $164(29.4 \%)$ \\
\hline & Strongly Agree & $346(61.7 \%)$ \\
\hline
\end{tabular}

Hypothesis 1: There is no effective policy that maintains and sanctions employers/employees against sexual harassment in the workplace or court.

5.1.5 Table 5: reveal that the partial correlation $(r=0.044, p=0.152)$ between the variables suggests that there is no effective control of the prevalence of sexual harassment among the legal professionals in the workplace or court. Therefore, the null hypothesis suggesting that there is no effective policy that sanctions employers/employees against sexual harassment in the workplace or court can be accepted ( $\mathrm{p}>0.05)$.

Table 5: Partial correlation analysis

\begin{tabular}{|c|c|c|c|c|}
\hline $\begin{array}{l}\text { Control } \\
\text { Variable }\end{array}$ & Continuous variable & & $\begin{array}{l}\text { Have you ever } \\
\text { experienced any } \\
\text { form of sexual } \\
\text { harassment at } \\
\text { workplace? }\end{array}$ & $\begin{array}{l}\text { Have you handled any } \\
\text { form of sexual } \\
\text { harassment } \\
\text { workplaces' case in } \\
\text { your firm or court? }\end{array}$ \\
\hline \multirow{4}{*}{$\begin{array}{l}\text { Was the case } \\
\text { adjudicated on } \\
\text { judiciously and } \\
\text { expeditiously }\end{array}$} & Have & Correlation & 1.000 & 0.044 \\
\hline & $\begin{array}{l}\text { experienced any form of } \\
\text { sexual harassment at } \\
\text { workplace? }\end{array}$ & Significance & - & 0.152 \\
\hline & Have you handled any & Correlation & 0.044 & 1.000 \\
\hline & $\begin{array}{lr}\text { form of } & \text { sexual } \\
\text { harassment } & \text { at } \\
\text { workplaces' case in your } \\
\text { firm or court? }\end{array}$ & Significance & 0.152 & - \\
\hline
\end{tabular}

Hypothesis 2: there is no relationship between awareness of the lawyers about the empowerment of the National Industrial Court of Nigeria and it ability to prevent the workplaces from sexual harassment.

5.1.6 The chi-square test $\chi 2=281.512, p$-value $=0.000(p<0.05)$ revealed that there is a significant association between the awareness of the lawyers about the empowerment of the National Industrial Court of Nigeria and its ability to prevent the workplaces from sexual harassment (Table 6). Based on the evidence above $(p<0.05)$, the null hypothesis stating that there is no relationship between awareness of the lawyers about the empowerment of 
the National Industrial Court of Nigeria and its ability to prevent the workplaces from sexual harassment can be rejected.

Table 6: Determinant of awareness of lawyers about NICN and its ability to address SH using Pearson Chi-square

\begin{tabular}{|c|c|c|}
\hline Items & $\begin{array}{l}\text { Pearson Chi- } \\
\text { square }\end{array}$ & Signif. \\
\hline $\begin{array}{l}\text { Do you know that the National Industrial Court of Nigeria has been } \\
\text { given the power to adjudicate on sexual harassment at the workplace } \\
\text { cases by virtue of section } 254 \mathrm{C}(\mathrm{g}) \text { of the } 1999 \text { Constitution as amended? } \\
\text { Do you think only the National Industrial Court of Nigeria can sensitize } \\
\text { and sanitize workplaces from sexual harassment? }\end{array}$ & 281.512 & 0.000 \\
\hline
\end{tabular}

Hypothesis 3: Prolonged exposures to sexual harassment have neither led to the development of coping mechanism nor mask its true nature and consequences on the victim.

5.1.7 According to the regression analysis Table 7, adjusted R-square is $62.8 \%$ variance of the participants' feelings when sexually harassed in the workplace and its consequence majorly signifies (endurance/tolerance). Based on the $62.8 \%$ prolonged exposure to sexual harassment, there is likelihood that it would have impacted the victims' feelings and their reactions towards being indifferent or mask its true consequences. Also, since $p<0.05$ implies that applied regression model is statistically significant, the null hypothesis stating that the prolonged exposure to sexual harassment have neither led to the development of coping mechanism nor mask its true nature on the victim is rejected.

Table 7: Regression analysis

\begin{tabular}{clcccccc}
\hline $\begin{array}{c}\text { Dependent } \\
\text { Variable }\end{array}$ & $\begin{array}{c}\text { Independent } \\
\text { Variables }\end{array}$ & $\begin{array}{c}\text { R- } \\
\text { square }\end{array}$ & $\begin{array}{c}\text { Adjusted } \\
\text { R-square }\end{array}$ & F & Signif. & B-constant & $\begin{array}{c}\text { Standardized } \\
\text { Beta }\end{array}$ \\
\hline Duration & $\begin{array}{l}\text { Feeling when } \\
\text { sexually harassed } \\
\text { atworkplace }\end{array}$ & 0.628 & 0.626 & 467.980 & 0.000 & 1.175 & 0.797 \\
$\begin{array}{l}\text { Consequences of } \\
\text { sexual harassment } \\
\text { at workplace }\end{array}$ & & & & & & 0.028 & 0.023 \\
\hline
\end{tabular}

Hypothesis 4: There is no relationship between the prevalence of sexual harassment in legal profession and the need for law prohibiting it.

5.1.8 The chi-square test $\chi 2=43.132, p$-value $=0.010(p<0.05)$ on (Table 8$)$ revealed that there is a significant association between the prevalence and the need for law prohibiting sexual harassment in the workplace. Based on the evidence above $(\mathrm{p}<0.05)$, the null hypothesis stating that there is no relationship between the prevalence of sexual harassment in the Nigerian legal profession and the need for law prohibiting it can be rejected.

Table 8: Determinant of the relationship between the prevalence of SH and the need for law prohibiting it

\begin{tabular}{|c|c|c|}
\hline Items & Pearson Chi-Square $(\chi 2)$ & Signif. \\
\hline $\begin{array}{l}\text { The forms of sexual harassment rampant in legal } \\
\text { profession? } \\
\text { Is there need for a law in Nigeria that punishes sexual } \\
\text { harassment at workplace }\end{array}$ & 43.132 & 0.010 \\
\hline
\end{tabular}

\section{Discussion of findings}

Our results have a lot of implications, and it provides support for generalization. On the first question, we settle that sexual harassment is prevalent in the Nigerian legal profession. This finding is in line with some researches stemming from common law jurisdiction. Victorian Equal Opportunity and Human Right Commission's survey (Toohey, 2012) revealed that $23.9 \%$ of 100 respondents experienced sexual harassment while working as lawyers or legal trainees in Victoria and $48 \%$ are aware of incidents of sexual harassment that occurred to their colleagues. Also, $67.2 \%$ were victims of sexually suggestive comments or jokes, $44.3 \%$ experienced intrusive questions about their private life, $41.6 \%$ were victims of unwelcome physical touch, and $38.9 \%$ were victims of unwelcome staring (Toohey, 2012).

In a 1990 survey conducted on young lawyers' division of the American Bar Association [ABA], (Tengku and Maimunah, 2000) noted that 78\% males and $85 \%$ females experienced one form of sexual harassment in the profession. Likewise, (Laband and Lentz, 1998) reported that 26\% of 604 male attorneys and $66 \%$ of 140 female attorneys, working in law firms experienced one form of sexual harassment from their colleagues, supervisors, and clients. In some American surveys observed by (Rhode, 2001), around half to two-thirds of female lawyers, and a quarter to half of female court personnel reported to have experienced sexual harassment and approximately three-quarters of female lawyers saw it as a challenge in the profession. (Lazar, 2016) noted that sexual harassment is a discriminatory and unprofessional practice among the American advocates. 
Meanwhile, these sexually harassing behaviours are gradually reducing due to the help of trainings, policy enforcement and the adoption of (resolution 302- which is provided to support the 1992 anti-harassment policy of the American Bar Association, to combat retaliation after reporting sexual harassment, as well as to create zero tolerance of sexual harassment in the American legal profession), when compared to the 90s studies.

Most Indian female lawyers also experienced sexual harassment at some point in the profession (Mishra, 2015). Sexual and experiences of gender discrimination permeate the Canadian legal profession (Kay, 2002). Brockman revealed that one-third females of 600 and 10\% males of 1,798 British Columbia lawyers admitted to have encountered unwanted sexual advances from other lawyers (Brockman, 1992b). In another study conducted by Brockman, it was reported that within a space of two (2) years, $34 \%$ women and $10 \%$ men in law practice observed their female colleague being subjected to unwanted sexual advances in their workplace (Brockman, 1992a). In fact, sexual harassment was perceived majorly as a form of discrimination against women in the profession (Laband and Lentz, 1998). English female lawyers revealed that sexual harassment is fact of life at United Kingdom law firms; of 1000 lawyers surveyed, 42\% experienced sexual harassment at work, from suggestive comments to propositioning and unwanted physical contact (Financial Times, 2018). Nicolson reported that some writers argued that sexual harassment rife in English law practice. In another study of Brockman reviewed by (Unikowsky, 2001) it was settled that sexual harassment is a perpetual act that demoralises the professional relations in law practice, and what is expected of this noble profession is zero tolerance for sexual harassment.

Regarding the perception of sexual harassment and gender, we found that there is a significant difference in the perception of sexual harassment by gender. The data suggest that female participants perceived sexual harassment more than the male participants. This finding is in contrast with that of Bello who found that $58.38 \%$ male and 53.51\% female Nigerian bank employees view gender harassment, sexual coercion and sexual harassment in a similar manner (Bello, 2016). In consistent with this finding, (Ekore, 2012) revealed the difference in gender perception in his study that $39.6 \%$ female respondents perceived sexual harassment more than the $38.1 \%$ male respondents. Likewise, some other researchers found that gender differs in experience, awareness, and definition of sexual harassment but, highly predominant on the female (Banerjee and Sharma, 2011; Rotundo et al., 2001). This could be due to the inequality in gender employment and believe that women are sex objects undermining their level of intelligence and knowledge. It could also be due to unequal number of gender participants selected for the survey, a need for further research.

From the study, Nigerian legal practitioners have a high level of knowledge about sexual harassment. This finding is similar with other previous studies which found that their participants have a high knowledge of factors that constitutes sexual harassment (Apaak and Sarpong, 2015). In contrast with our finding, some studies stated average knowledge of sexual harassment among their respondents (Gabriel and Panahon, 2017; Aditi et al., 2016) while some participants displayed a low knowledge of sexual harassment (Das and Rath, 2015). Nevertheless, with the high level of knowledge of sexual harassment exhibited among the Nigerian legal professionals, the subjects were neither secured nor prevented from being sexually harassed.

The first hypothesis demonstrated that there is no effective policy that sanctions employer/employee of sexual harassment in the workplace or court. This suggests the likely reason the participants' experience one form of sexual harassment to the other and the limited reported cases (about '9' sexual harassment cases have been decided in Nigeria since the NICN's constitutional empowerment). ${ }^{1}$ This probably indicates that the lack of report by the victims is not due to protection of reputation or importance of personal relations and culture, but absence of organisational structure with zero-tolerance for sexual harassment and punitive measures. Past research argues that organisational tolerance of sexual harassment determines response to such issue and the victim's perception or approach (Willness et al., 2007; Wasti and Cortina, 2002; Hulin et al., 1995).

This aligns with the open-comment of one of the participants;

'My experience took place years ago, when I was still very young and single. I really had nobody to report to, but a senior colleague and my pastor. Eventually, I was 'sacked' by my then boss. If there is a proper framework in place, no young lawyer should have to experience what I went through, which included near rape. Those responsible for strategizing against sexual harassment in the legal profession should see it as a serious calling'.

Hence, a preventive and reactive measures, ensuring safe and healthy work environment with emphasis on official code of conduct, ethical behaviours, operative complaint channels, monitoring occurrences of sexual

\footnotetext{
${ }^{1}$ See note 5 above; Dorothy Adaeze Awogu v. TFG Real Estate Limited, Suit No. NICN/LA/262/2013 (National Industrial Court, Lagos Division June 4, 2018). Abisola Akinsete Vs. Westerngeco Seismic Nigeria Limited, Suit No. NICN/LA/516/2012 (National Industrial Court, Lagos Division November 27th, 2014); Pastor (Mrs) Abimbola Patricia Yakubu v. Financial Reporting Council of Nigeria and Anor, Suit No. NICN/LA/673/2013 (National Industrial Court, Lagos Division November 24 ${ }^{\text {th }}$, 2016); Stella Ayam Odey Vs. Ferdinand Daapah and Cuso International (unreported), Suit No: NICN/ /CA/03/2016 (National Industrial Court, Calabar Division January 13 ${ }^{\text {th }}$, 2017); Dorothy Adaeze Awogu v. TFG Real Estate Limited, Suit No. NICN/LA/262/2013 (National Industrial Court, Lagos Division June 4, 2018); Others are still pending in Court.
} 
harassment, and punishment of policy violators will not only encourage victims to report issue of sexual harassment, but serve as an effective policy that sanctions sexual harassment in the workplace (Aina-Pelemo et al., 2018; Ramsaroop and Brijball, 2007). This finding is in contrast to previous studies which found that the reason for not reporting was due to fear of double victimization, importance of reputation, and personal relations, lack of courage, fear of disgrace, retaliation etcetera (Thomas, 2015; Buchanan et al., 2014).

On the second hypothesis, there is a legal platform where victims of sexual harassment violation can seek redress in Nigeria, but our data suggest that it is an inadequate social structure and cannot ensure effective enforcement. To buttress this finding, since the empowerment provisions of section 254C-(1) (f), (g), (h) and section 254C-(2) of the 1999 Constitution of the Federal Republic of Nigeria, Third Alteration Act, 2010 which conferred jurisdiction upon NICN to adjudicate on sexual harassment matters, and use ratified international treaties to that effect respectively (Aina-Pelemo et al., 2018), very few participants are aware of this jurisdictional power. So how can the public seek redress when majority of the lawyers are not aware of this fact? The probable reasons for this is; the basis of such power which is on mere guidelines from international treaties: CEDAW and ILO conventions, without local legislation nor precise punishment for violators, discretional-based decisions, no clear legislations, no organisational structure that tolerates zero harassment, employers are not mandated to provide internal policy, no complaint platform other than the NICN, no trainings, workshops, seminars etcetera, yet the Government believed to have created an avenue to bring cases of sexual harassment before the law.

In line with this finding, the Ministry of Human Resources of Malaysia provided the organisations with code of practice regarding the prohibition, prevention and redressal of sexual harassment in the workplace but, majority are still not aware because it lacks legal backing and cannot serve as law (Spencer and Barnett, 2011). Likewise, Chaudhuri found that 50 of 77 victims of his survey are not aware of the Complaints Committee for Redressal of sexual harassment grievances after the 1997 Vishaka's guidelines of the Supreme Court of India, which was based on mere international treaties and could not reprimand the perpetrators (Chaudhuri, 2007). This result was reiterated by Yadav, although the participants were medical professionals as compared with this study that deals with legal practitioners (Yadav, 2007). In spite of the provisions of the Vishaka's guidelines, educational officials who were supposed to be the guidance of the pupil were neither aware nor include the issue of sexual harassment in their school cirruculum (Leach and Sitaram, 2007). This signifies that awareness was lacking and could contribute to the prevalence of sexual harassment among professionals.

With respect to the effect of prolonged sexual harassment on the participants, the data suggest that the major coping mechanism adopted was endurance/tolerance to mask the true effect of sexual harassment. This indicates that the longer the duration of harassment, the decrease in feelings of the victims, consequently encouraging the perpetrators (Page and Pina, 2015). Some see the option as the only way for career building or a part of life (Akhtar, 2013), and some English lawyers left such issue unchallenged due to the importance of personal relations, reputation and other common factors (Sommerlad, 2016; Nicolson, 2005). This indicates that the legal professionals suffer in silence like other professions. Meanwhile, the fact that they submit to or tolerate this sexual demand does not certainly mean that it is satisfactory. Behaviour may be tolerated and yet unwelcome at the same time (Fitzgerald, 2004). The likelihood for submitting to such conduct may be closely related to the power differential between the parties and the implied understanding that lack of co-operation could result in some form of disadvantage.

In line with this finding, $69.7 \%$ of 447 private sector and $52.0 \%$ of 300 university samples surveyed reported 'just put up with it' as the coping strategy adopted for management of sexual harassment (Schneider et al., 1997). Corroboratory, it was reported that sexual harassment is a norm for majority of New-Zealand female lawyers to put up with in other to rise to the top in the profession (Tapaleao, 2018). Likewise, the survey conducted among selected Nigerian bank workers revealed the tolerance of distress as a ground for coping, which might further lead to workplace deviances and high attrition rate (Amazue et al., 2014). In disparity with our finding, the main coping strategies adopted by their respondents were to report to the authority (Arulogun et al., 2013). This research finding is also consistent with some previous studies which found that the culture of silence rather than speaking out is the major means of managing sexual violence within the Nigerian community (Awosusi and Ogundana, 2015; Fapohunda, 2014).

On the fourth hypothesis, our result supported the postulation that the prevalence of sexual harassment in the profession has a relationship with the need for law. Majority of participants agreed to the need for law prohibiting sexual harassment in the profession. In support of this assertion, most of the participants further agreed that the long-term solution to sexual harassment in the legal profession should include; mandatory provision of internal official policy, amendment of the legal practitioners' Act/Rules to classify sexual harassment as a punishable professional misconduct and setting up a body with confidential procedure to address issues of sexual harassment in the profession. 


\section{Conclusion}

The current research provides the first empirical evidence-based survey on sexual harassment in the Nigerian legal sector. It highlighted the prevalence of sexual harassment among the advocates and solicitors of the Supreme Court of Nigeria. This study found sexual harassment to be a major challenge in the Nigerian workplaces which should not be left unaddressed. If not nationally addressed by the country, it is suggested that it should be urgently addressed professionally; by classifying such deviant act as a professional misconduct that is punishable under the G. N. No 69, Legal Practitioners Act, Chapter 207, LFN. Rules of Professional Conduct, 2007.

These Rules should expressly prohibit lawyers from sexually harassing their colleagues just like the United Kingdom $^{1}$, Canada $^{2}$, and US ${ }^{3}$ that prohibits and provides tackling guides on sexual harassment for all chambers to further protect and better help the lawyers defend themselves as well as others. Although, behavioural patterns or social misconduct of some lawyers might be difficult to tame, because of their manipulative act and ability to maximise the loop holes in Rules. However, categorization of sexual harassment as a professional misconduct with provision of punitive measures will be a good start and further create fear of being disbarred from the profession in the lawyers. Individually and collectively, we can eradicate sexual harassment from this profession, victims should learn to build their evidence, speak to friend or colleague or report to higher authority and others. Also listening, being patient and not blaming victims of sexual harassment will help support their confidence in speaking out. With emphasis, enacting a national law or prohibiting sexual harassment might not totally eradicate sexual harassment from the profession, but it will undoubtedly put a check and provide means of seeking redress for victims. In addition, the recent provision of secretariat for lodging gender-biased offenses in Abuja (Edokwe, 2018), Federal Capital Territory, Nigeria is applaudable, but when the lawyers lack basic internal protection how can they help the society? Hence, lawyers should be secured, equipped and trained on sexual harassment.

Finally, Nigeria as a party to CEDAW and ILO, has subjected itself to passing legislation and providing adequate policies which practically prohibit sexual harassment in the workplace. So, the mere empowerment of the NICN to adjudicate on issues of sexual harassment is inadequate and cannot fill the lacuna of local legislations with the prevalence of sexual harassment in the Nigerian work-setting. We therefore say, it does appear that there is not only a need for legal protection of the Nigerian legal professionals from sexual harassment in the profession, but there is also an urgent need for a comprehensive local legislation with clarity and explicit procedures for prevention, management, and protection of employees in employment, educational institutions and training workshops against sexual harassment in Nigeria.

\section{Limitation of study}

The strength of this study is that it fills the gap of no empirical survey in the Nigerian legal sector vis-a-vis sexual harassment. Drawing sample from an urban part of the country makes the generalisability high, as the fraction drawn, are saddled with the responsibility of defending the masses. Lawyers practicing in other urban parts were not included in the sample frame which is a limitation; a gap is recommended for further research. Due to the sensitivity of the topic, the questionnaires structured anonymity of respondents, the mixed-methods used in data collection might have hindered the paper-and-pencil participants from disclosing the accurate picture since they were approached one-on-one. Further research could be done by using a more effective method. Also, the participants were not asked the position of the main perpetrators of the sexual harassment they experienced- a colleague, head of chambers, principal partner or client, though some specified that in the open comment section.

Another possible limitation of this study could be the use of all genders for the survey, although numerous researches (Lazar, 2016; Toohey, 2012; Kay and Gorman, 2008; Rhode, 2001) settle that female lawyers are more likely to be sexually harassed than their male counterparts. Therefore, a further research is recommended to be conducted on a particular gender especially the females. This research did not address the issue of the rank of lawyers more prone to sexual harassment nor at what year of post-call vis-à-vis duration of being subject to sexual harassment in the workplace. Although we recognized that age or level of education and legal experience does not prevent a person from being sexually harassed (Reena and Saheab, 2014), and harassment mostly

\footnotetext{
${ }^{1}$ Bar Council Equality and Diversity Guides Tackling Sexual Harassment: Information for Chambers. [Amended December, 2015]. Retrieved $\quad$ March $\quad 5, \quad$ from: $<$ https://www.barcouncil.org.uk/media/409759/dealing_with_sexual_harassment_in_chambers_december_2015.pdf>; Also see Rules C 69 of the Bar Standard Board, [2 $2^{\text {nd }}$ ed., April 2015] from:https://www.barstandardsboard.org.uk/media/1731225/bsb_handbook_sept_2015.pdf ${ }^{2}$ The Law Society of Upper Canada, Rules of Professional Conduct, Section 6.3 'Sexual Harassment' [Amended October, 2014]. Retrieved March 5 2019, from: <https://www.lsuc.on.ca/list.aspx?id=671>

Model Rules of Professional Conduct. September, 2016 Retrieved March 5, 2019 from: https://www.americanbar.org/groups/professional_responsibility/publications/model_rules_of_professional_conduct/rule_8_4_misconduct.ht $\mathrm{ml}$; Also see American Bar Association: ABA adopts new policy to combat sexual harassment in the legal workplace. [web log post]. Retrieved March 5, 2018 from; https://www.americanbar.org/news/abanews/aba-news-archives/2018/02/aba adopts new polic.html
} 
occurs at the early stages of employment (Toohey, 2012), hence we recommend a further research and also on the positive impact of sexual harassment as this study focused more on the negative impact of sexual harassment in the profession.

\section{Recommendations}

- The President of the Nigerian Bar Association should address/communicate to all chambers urging a zero-tolerance approach to sexual harassment within the profession.

- Mandatory provision of comprehensive internal official policy for all workplaces and national domestication of all the International treaties ratified by the Federal Government of Nigeria regarding sexual harassment in the workplace.

- Amendment of the legal practitioners' Act/Rules to accommodate a section to prohibit and address sexual harassment in the legal profession.

- A body with confidential procedure should be set-up by all organisations to address issue of sexual harassment when reported in the organisation and they should be subject to check by external higher authority.

- If the harasser is the main employer, or principal employer, there should be an external complaint committee or body to entertain issue of such rather than saddling the NICN with the sole responsibility of adjudicating on sexual harassment matters.

- The employers should be burdened with the responsibility of ensuring a workplace free from all forms of harassments with emphases on self-control and modest dress sense, by organising trainings, workshops, seminars and different awareness measures to sensitize employees in other to create a zerotolerance organisational structure.

- Nigerian Bar Association, Legal Disciplinary Committee, in collaboration with the NICN should make it a priority to rid the profession of sexual harassment by organising diverse professional development programs to sensitize/encourage the victims to report or speak out and bringing to book those who indulge in such act.

\section{Conflict of Interest}

Authors declare that there is no conflict of interest regarding this research.

\section{Compliance with Ethical Standards}

All procedures followed in this survey involving human participants were in accordance with the ethical standards of Research Training Development Centre, Sharda University, Greater-Noida, Uttar-Pradesh, and also in conformity with the 1964 Helsinki declaration (as amended).

\section{Acknowledgement}

We extend our heartfelt appreciations to the following solicitors and advocates of the Supreme Court of Nigeria (Sawyerr E., Omole, S., Agboneni, O. and Okene, H.) for their support in data collection, and we appreciate Oloketuyi, S. for her constructive comments on earlier drafts.

\section{Reference}

Abe, I. (2012). Defining and Awareness of Sexual Harassment among Selected University Students in Lagos Metropolis, Nigeria. Journal of Emerging Trends in Educational Research and Policy Studies, 3(3), 212 218.

Abodunrin, O. L., Adeoye, O. A., Adeomi, A. A. and Ake, T. M. (2014). Prevalence and forms of violence against health care professionals in a South-Western city, Nigeria. Sky Journal of Medicine and Medical Sciences, 2(8), $067-072$.

Adamolekun, O. (1989). Sexual harassment on campus: A counsellor's reflection. Nigerian Journal of Counselling and Development, 4, 53-57.

Adekoya, F. (2009). The changing face of the legal profession and the impact of gender and diversity in Nigeria. www.ibanet.org: $\quad$ https://www.ibanet.org/Article/NewDetail.aspx?ArticleUid=fbdae64d-c831-461b-93. Accessed 7 February 2018.

Adenugba, A. A., and Ilupeju, C. O. (2012). Working Conditions of Female Marketers in Selected New Generation banks in Ibadan. Nigeria Journal of Research in National Development, 10(2), 199 - 207.

Aditi, G., Sangeetha, P., and Binu, E. M. (2016). Knowledge of Sexual Harassment among the Undergraduate students in Udupi district. Nitte University Journal of Health Science, 6(2), 4 - 9.

Aina, A. D., and Kulshretha, P. (2017). Sexual Harassment in Educational Institutions in Delhi' NCR, (India): Level of Awareness, Perception and Experience. Sexuality and Culture, 21(1), 106-126. 
Aina-Pelemo, A. D., Mehanathan, M. C. Kulshrestha, P. (2018). Sexual Harassment at Workplace: Judicial Impact in Nigeria and India. Indian Journal of Law and Human Behaviour, 4(2), 211 - 225.

Aina-Pelemo, A., and Saluja, S. (2018). Comparative Analysis of Sex-Selection in Nigeria and India. International Journal of Humanities and Social Science Studies, 4(6), 70-88.

Aja-Okorie, U. (2014). Sexual Harassment / Victimization in Nigeria Universities: An impediment to Effective University Administration. Journal of Harmonized Research in Management, 1(1), 18 - 29.

Akanle, F. F. (2011). Sexual Coercion of Adolescent Girls in Yoruba Land of Nigeria. Current Researches on Journal of Social Science, 3(2), 132-138.

Akhtar, C. (2013). Sexual harassment at workplace and in educational institutions: A case study of District Srinagar, Kashmir. International NGO Journal, 8(3), $54-60$.

Akinfala, F. F., and Komolafe, T. (2017). Sexual Harassment as a Predictor of Organisational Outcomes. African Journal for the Psychological Study of Social Issues, 20(1), 60-73.

Alooma, A. G., and Atadiose, S. (2014). Impact of Target Deposit Mobilization on Unethical Issues and Employee' Dissatisfaction in Nigerian Banking Sector. American International Journal of Contemporary Research, 4(10), 120-132.

Amazue, L. O., Onyishi, I. E., and Amazue, L. E. (2014). Surface acting and distress tolerance as predictors of workplace deviance among Nigerian commercial bank workers. African Journal of Business Management, $8(15), 582-587$.

Amos, I. O. (2016). Factors Affecting Female Police Officers' Performance in Akure Community, Ondo State, Nigeria. Research on Humanities \& Social Sciences, 6(3), 42-52.

Apaak, D., and Sarpong, E. O. (2015). Knowledge Level and Incidence of Sexual Harassment in Sports: Views of Ghanaian Female University Athletes. Journal of Educational and Social Research, 5(3), 121 - 130.

Arulogun, O. S., Omotosho, I. K., and Titiloye, M. (2013). Experience of sexual harassment and coping strategies among students of the School of Nursing of a tertiary hospital in SouthWest, Nigeria. International Journal of Nursing and Midwifery, 5(4), 70-75.

Awosusi, O. A., and Ogundana, F. C. (2015). Culture of Silence and Wave of Sexual Violence in Nigeria. AASCIT Journal of Education, 1(3), 31 - 37.

Banerjee, A., and Sharma, B. (2011). Gender differences in Perception of Workplace Sexual Harassment among future Professionals. Industrial Psychiatry Journal, 20(1), $21-24$.

Bello, S. M. (2016). Gender Differences in Perception of Sexual Harassment among Nigerian Banks' Employees. Proceedings of ISER 29th International Conference, UAE (pp. 21-26). Dubai: Proceedings of ISER. 22nd April 2016, ISBN: 978-93-85973-83-3. 21-26.

Berdahl, J. L. (2007). Sexual Harassment of Uppity Women. Journal of Applied Psychology, 92(2), 425 - 437.

Brockman, J. (1992b). Bias in the legal profession: perceptions and experiences. Alberta Law Review, 30(3), 747-808.

Brockman, J. (1992a). Gender Bias in the Legal Profession: A Survey of Members of the Law Society of British Columbia. Queen's Law Journal, 17, 91-146.

Brockman, J. (2001). Gender in the Legal Profession: Fitting or Breaking the Mould. Vancouver: University of British Columbia Press.

Brockman, J. (1994). Leaving the Practice of Law: The Wherefores and the Whys. Alberta Law Review, 32(1), $116-180$.

Brockman, J. (1997b). The Use of Self-Regulation to Curb Discrimination and Sexual Harassment in the Legal Profession. Osgoode Hall Law Journal, 35(2), 209-241.

Chaudhuri, P. (2007). Experiences of sexual harassment of women health workers in four hospitals in Kolkata, India. Reproduction of Health Matters, 15(30), 221-229.

Clancy, K., Nelson, B. H., Rutherford, R. G., and Hinde, J. N. (2014). Survey of Academic Field Experiences (SAFE): Trainees Report Harassment and Assault. PLOS ONE, 9(7), e102172. doi: 10.1371/journal.pone.0102172

Cohn, C. (2013). India \& Nigeria: Similar Colonial Legacies, Vastly Different Trajectories: An Examination of the Differing Fates of Two Former British Colonies. Cornell International Affairs Review, 7(1), (online) http://www.inquiriesjournal.com/a?id=1483 (Accessed 7 February 2019).

Cortina, L. M., and Berdahl, J. L. (2008). The Sage Handbook of Organisational Behavior. In C. A. Cooper, Sexual Harassment in Organisations: A Decade of Research in Review (pp. 470 - 497). CA, Thousand Oaks: Sage.

Das, M. P., and Rath, D. P. (2015). The Low Level of Awareness and Impact of Intervention about Sexual Harassment. International Journal of Social Science \& Humanities, 3(4), 283 - 286.

Ejieke Maduka v Microsoft Nigeria Limited \& 2 Ors, NICN/LA/492/2012 (National Industrial Court, Lagos Division December $19^{\text {th }}, 2013$ ). 
Ekore, J. O. (2012). Gender differences in perception of sexual harassment among university students. Gender and Behavior, 10(1), 4358 - 4369.

Ezichi, I., F., Uroko,I, and Eskay, M. (2013). The Problem of Sexual Abuse in Nigerian Socio-Religious Society. International Journal of Research in Arts and Social Sciences, 5, 498 - 512.

Fapohunda, M. T. (2014). Gender Differences in Perceptions and Experiences of Sexual Harassment in the Workplace. Global Journal of Management and Business, 1(2), 036 - 044.

Financial Times (2018). Women lawyers say sexual harassment is fact of life at UK law firms. (News report) https://www.ft.com/content/a1688488-211a-11e8-a895-1ba1f72c2c11 (Accessed 8 March 2019).

Fitzgerald, L. F., and Alayne, J. O. (1991). Perceptions of Sexual Harassment: The influence of Gender and Academic Context. Psychology of Women Quarterly, 15, 281 - 294.

Fitzgerald, L. F., Drasgow, F., Hulin, C. L., Gelf, M. J., and Magley, V. J. (1997). Antecedents and Consequences of Sexual Harassment in Organisations: A Test of an Integrated Model. Journal of Applied Psychology, 82(4), 578-589.

Fitzgerald, L. F. (2004). In Mackinnon, C. A. \& Siegel, R. B. (Eds.), Directions in Sexual Harassment Law: Who says? legal and psychological constructions of women's resistance to sexual harassment (pp. 94 - 110). New Haven: Yale University Press.

Gabriel, A. G., and Panahon, H. P. (2017). Drawing the Demarcation Line: An Analysis of Sexual Harassment in Selected Learning Institutions in Nueva Ecija, Philippines Using Blumer's Interactionism Model. Open Access Library Journal, 4, e3328. http://dx.doi.org/10.4236/oalib.1103328

Gupta, R. (2014). Sexual Harassment at Workplace. Haryana : LexisNexis.

Haas, T. S. G., and Hoing, M. (2009). Sexual Harassment and Health among Male and Female Police Officers. Journal of Occupational Health Psychology, 14(4), 390 - 401.

Haspels, N., Zaitun, M. K., Constance, T., and McCann, D. (2001). Action against Sexual Harassment at Work in Asia and the Pacific. http://www.ilo.org/wcmsp5/groups/public/---asia/---robangkok/documents/publication/wcms_bk_pb_159_en.pdf Accessed 8 March 2019.

Hersch, J. (2015). Sexual harassment in the workplace. (IZA World of Labour) 188, 1-10. doi:10.15185/izawol.188.

Hulin, C. L., Fitzgerald, L. F., and Drasgow, F. (1995). Organizational influences on sexual harassment. In M. Stockdale (Ed.), Sexual harassment in the workplace (Vol. 5, pp. 127-150). Thousand Oaks, CA: Sage.

Idris, H., Adaja, J., Audu, S., and Aye, G. A. (2016). Analysis of the Causes and Effects of Sexual Harassment on the Performance of Female Employees in some Selected Organisations in Kogi State, Nigeria. International Journal of Democratic and Development Studies, 2(2), 31-39.

Ige, A.Y., and I. A. Adeleke. (2012). Evaluating the role of Culture on Sexual Harassment: the case of Nigerian Organizations. (online) ilera2012.wharton.upenn.edu/RefereedPapers/IgeAY\%20AdelekeIA\%20ILERA.pdf. (Accessed 8 March 2019) .

Imonikhe, J., Aluede, O., and Idogho, P. (2012). A Survey of Teachers' and Students' Perception of Sexual Harassment in Tertiary Institutions of Edo State, Nigeria. Asian \Social Science, 8(1), $268-274$.

Inyang-Etoh, E. C., and Ekanem., A. M.( 2016). Child-Sex Preference and Factors that Influenced such choices among women in an Obstetric Population in Nigeria. Open Access Library Journal, 03(10), 1-10.

Ismail, N. M., Chee, L. K., and Bee, C. F. (2007). Factors Influencing Sexual Harassment in the Malaysian Workplace. Asian Academy of Management Journal, 12(2), 15 - 31.

Izugbara, C. O. (2001). Tasting the Forbidden Fruits: The Social Context of Debut Sexual Encounters Among Young Persons in a Rural Nigerian Community. The African Anthropologist, 8(1), 96 - 107.

Izugbara, C. O. (2004). Understanding Human Sexuality Seminar Series 2: Patriarchal Ideology and Discourses of Sexuality in Nigeria. (online) http://www.arsrc.org/downloads/uhsss/izugbara.pdf (referenced 18 March, 2019).

Joubert, P., Wyk, V. C., and Rothmann, S. (2011). The effectiveness of sexual harassment policies and procedures at higher education institutions in South Africa. SA Journal of Human Resource Management / SA Tydskrif vir Menslikehulpbronbestuur, 9(1), 1-10.

Kay, F. M. (2002). Crossroads to innovation and diversity: the careers of women lawyers in Quebec. McGill Law Journal, 47(4), $699-742$.

Kay, F., and Gorman, E. (2008). Women in the Legal Profession. Annual Review of Law and Social Science, 4, 299 - 332.

Laband, D. N., and Lentz, B. F. (1998). The effects of sexual harassment on job satisfaction, earnings, and turnover among female lawyers. Industrial Labour Relations Review, 51(4), $594-607$.

Ladebo, O. J. (2003). Sexual Harassment in Academia in Nigeria: How Real? African Sociological Reviews, 7(1), $117-130$.

LawPavilion. (2016). "Sexual Harassment in Tertiary Educational Institutions Prohibition Bill, 2016". (Law Pavilion), Retrieved 9 March, 2019 from: https://awpavilion.com/blog/sexual-harassment-in-tertiary- 
educational-institutions-prohibition-bill-2016/

Leach, F., and Sitaram, S. (2007). The sexual harassment and abuse of adolescent schoolgirls in South India. Education, Citizenship and Social Justice, 2(3), 257 - 277.

Loughnan, S., Pina, A., Vasquez, E. A., \& Puvia, E. (2013). Sexual Objectification Increases Rape Victim Blame and Decreases Perceived Suffering. Psychology of Women Quarterly, 37(4), 455-461.

Mezie-Okoye, M. M., and Alamina, F. F. (2014). Sexual Violence among Female Undergraduates in a Tertiary Institution in Port Harcourt: Prevalence, Pattern, Determinants and Health Consequences. African Journal of Reproductive Health, 18(4), 79-85.

Mishra, S. K. (2015). Women in Indian Courts of Law: A Study of Women Legal Professionals in the District Court of Lucknow, Uttar-Pradesh, India. E-cadernos ces, 24, 78 - 101.

Nicolson, D. (2005). Demography, discrimination and diversity: a new dawn for the British legal profession? International Journal of the Legal Profession, 12(2), 201 - 228.

Nwaeke, L. I. (2015). Narcissism and Sexual Harassment in Organisations: Their Dynamics and Coping. International Journal of Science \& Techology, 4(1), 129 - 141.

O'Connor, M., Gutek, B. A., Stockdale, M., Geer, T. M., and Melanc, R. (2004). Explaining Sexual Harassment Judgments: Looking Beyond Gender of the Ratter. Law and Human Behaviour, 28(1), 69-95.

Odebiyi, A. I. (1992). Conception of AIDS and its prevention among students in a Nigerian University. Journal of the Royal Society of Health, 112(2), $59-63$.

Ohagwu, C. C., Eze, C., Eze, J., Odo, M. C., Abu, P. O., and Ohagwu, C. (2014). Perception of Male Gender Preference among Pregnant Igbo Women. Annals of Medical and Health Sciences Research, 4(2), 173-178.

Okeke, T., Enwereji, J., Okoro, O., Iferikigwe, E., Ikeako, L., Ezenyeaku, C., et al. (2015). Desire for Prenatal Gender Disclosure among Primigravidae in Enugu, Nigeria. Patient and Adherence, 9, 429-433.

Okoro, F. I., and Obozokhai, O. (2005). Sexual Harassment: The Experience of Out-Of-School Teenagers in Benin City. Nigeria African Journal of Reproductive Health, 9(3), 118 -127.

Page, T. E., and Pina, A. (2015). Moral disengagement as a self-regulatory process in sexual harassment perpetration at work: A preliminary conceptualization. Aggression and Violent Behaviour, 21, 73 - 84.

Quick, J. C., and McFadyen, M. A. (2016). Sexual Harassment: Have We Made Any Progress? Journal of Occupational Health Psychology, 22(3), 286-298.

Ramsaroop, A., and Brijball, P. (2007). The Prevalence and Nature of Sexual Harassment in the Workplace: A Model for Early Identification and Effective Management Thereof. SA Journal of Industrial Psychology, 33(2), 25 - 33.

Reena, M., and Saheab, O. (2014). Sexual Harassment against Women at Educational Institutions. International Journals of Science and Research, 3(12), $914-917$.

Rhode, D. L. (2001). The Unfinished Agenda: Women and the Legal Profession. Chicago: [American Bar Association Commission on Women in the Profession]. (online) http://womenlaw.stanford.edu/pdf/aba.unfinished.agenda.pdf (Accessed 8 February 2019).

Rotundo, M., Nguyen, D. H., and . Sackett, P. R. (2001). A meta-analytic review of gender differences in perceptions of sexual harassment. Journal of Applied Psychology, 86(5), 914 - 922.

Udogwu, F. (2016). A Case Study on Violence against Nurses in Nigeria and Recommendations in Reducing the Violence. South American Journal of Nursing, Special Edition, 1-7.

Shap, J., and Sorsby, A. (1995). Starting Practice: Work and Training at the Junior Bar. Sheffield: University of Sheffield Press.

Sommerlad, H. (2002). Women Solicitors in a Fractured Profession: Intersections of Gender and Professionalism in England and Wales. International Journal of the Legal Profession, 9, 213.

Sommerlad, H. and Sanderson, P. (1998). Gender, Choice and Commitment: Women Solicitors in England and Wales and the Struggle for Equal Status. Aldershot: Dartmouth.

Spencer, L., and Barnett, J. T. (2011). When Men Are Sexually Harassed: A Foundation for Studying Men's Experiences as Targets of Sexual Harassment. Speaker \& Gavel, 48(2), 53 - 67.

Taiwo, M., Omole, O. C., and Omole, O. E. (2014). Sexual Harassment and Psychological Consequence among Students in Higher Education Institution in Osun State, Nigeria. International Journal of Applied Psychology, 4(1), 13 - 18.

Thomas, A. (2015). Incidents of Sexual Harassment at Educational Institutions in India: Preventive Measures and Grievance Handling. International Journal of Recent Advances in Multidisciplinary Research, 02(03), $0317-0322$.

Tengku, O. and Maimunah, A. (2000). A Guide to the Malaysian Code of Practice on Sexual Harassment at Workplace. Kuala Lumpur: Leeds Publications.

Victorian Equal Opportunity and Human Rights Commission. (2012). Changing the rules: the experiences of female lawyers in Victoria. Victoria, Australia (Victorian Equal Opportunity and Human Rights Commission). Karen, Toohey. 
Vosylis, R., Malinauskienė, O., and Žukauskienė, R. (2012). Comparison of Internet-Based Versus Paper-andPencil Administered Assessment of Positive Development Indicators in Adolescents' Sample. Psichologija, 45, 7 - 21 .

Wass, V., and McNabb, R. (2006). Pay, Promotion \& Parenthood amongst Women Solicitors. Work, employment and society, 20(2), $289-308$.

Wasti, S. A., and Cortina, L. M. (2002). Coping in Context: Sociocultural Determinants of Responses to Sexual Harassment. Journal of Personality and Social Psychology, 83(2), 394 - 405.

Willness, C. R., Steel, P., and Lee, K.( 2007). A Meta-analysis of the Antecedents and Consequences of Workplace Sexual Harassment. Personnel Psychology, 60, 127-162.

Yadav, M. (2007). Sexual Harassment of Women: Current Scenario of Indian Hospitals. Journal of Indian Academy of Forensic Medicine, 29(4), 0971 - 0973.

Yusuf, N. (2008). Experience of Sexual Harassment at work by female employees in a Nigerian. Journal of Human Ecology, 30(3), 179 - 186. 